\title{
MITOCHONDRIAL-DNA DIVERSITY AND THE ORIGIN OF THE MENIDIA CLARKHUBBSI COMPLEX OF UNISEXUAL FISHES (ATHERINIDAE)
}

\author{
ANTHONY A. ECHELLE, \\ Zoology Department, Oklahoma State University, Stillwater, OK 74078 \\ Thomas E. Dowling, Craig C. Moritz, and Wesley M. Brown \\ Museum of Zoology and Department of Biology, University of Michigan, Ann Arbor, MI 48109
}

\begin{abstract}
Restriction-endonuclease analysis of mitochondrial DNA (mtDNA) of the unisexual $M$. clarkhubbsi complex and close sexual relatives indicated that the unisexual complex arose through multiple, nonreciprocal hybridizations involving females of $M$. peninsulae. High-resolution analyses using restriction endonucleases that cleave at 4-bp sites revealed mtDNA sequence diversity that was low among unisexuals but high among individuals of $M$. peninsulae. The identification of $M$. peninsulae as a parent of the unisexuals conflicts with some details of previous allozyme comparisons. One possibility is that the unisexuals were derived from hybridization involving $M$. beryllina and a recently extinct form of $M$. peninsulae.

In contrast to the unisexuals, contemporary hybrids of $M$. peninsulae and $M$. beryllina are formed by reciprocal matings. The origins of extant unisexual lineages from nonreciprocal hybridizations, together with their low mtDNA diversity relative to the matemal ancestor, implies strong constraints on origins of unisexuality via hybridization. Data on reproduction by contemporary $F_{1}$ hybrids reveal one form of genetic/developmental constraint: $M$. peninsulae and $M$. beryllina may now have diverged beyond the point where the hybrid origin of new unisexual lineages is possible.
\end{abstract}

Received April 12, 1988. Accepted February 9, 1989

Unisexuality is rare among animal species (Bell, 1982). Among vertebrates, only about 50 different unisexual forms are known, although each typically includes a number of identifiable clones. Two major and mutually compatible hypotheses have been proposed to explain the rarity of unisexuality in animals: 1) cytological/developmental barriers to the loss of sexual reproduction and 2) adaptive advantages associated with sexual reproduction (Williams, 1975; Maynard Smith, 1978; Bell, 1982). To evaluate the first hypothesis, genetic constraints on the origin of unisexual lineages from bisexual species must be understood (Templeton, 1982; Lynch, 1984; Moritz et al., 1989a). In this paper, we use restriction-endonuclease analysis of mitochondrial DNA (mtDNA) to identify some of the genetic factors that may be important for silverside fishes (Menidia, Atherinidae).

Brackish waters of the northern and western coasts of the Gulf of Mexico support an

\footnotetext{
1 Present address: Department of Zoology, University of Queensland, St. Lucia, QLD 4067, Australia.
}

assemblage of silversides that includes two bisexual species $(M$. beryllina and $M$. peninsulae) and a number of all-female forms ("allozyme classes") that we call the $M$. clarkhubbsi complex (Echelle et al., 1989). Tests employing four different allozyme classes of the unisexual complex demonstrated that reproduction was by gynogenesis (Echelle et al., 1989). In gynogenesis, the eggs have unreduced chromosome numbers, and sperm are required only to initiate cleavage divisions. Because the sperm make no genetic contribution, the offspring are genetically identical to their mother.

Allozyme surveys have detected ten different genotypes (allozyme classes) within the $M$. clarkhubbsi complex (Echelle et al., $1983,1989)$. The various classes differ at one to four of six variable loci, with the two most common classes (A and B) differing at a single locus. The members of this complex, like most unisexual vertebrates (Cole, 1975; Schultz, 1977; Darevsky et al., 1985; Dawley and Bogart, 1989), apparently arose by interspecific hybridization. The allozyme composition of the unisexuals suggests that they arose through multiple hybridization events between $M$. beryllina and 
a "missing ancestor" more similar to $M$. peninsulae than to any other bisexual species (Echelle et al., 1983, 1989). However, phylogenetic considerations were ambiguous regarding whether the missing ancestor was more closely related to $M$. peninsulae or to another species, $M$. colei (Echelle et al., 1983).

$M$. beryllina and $M$. peninsulae occur together in estuarine bays and brackish pools over an extensive coastline from the Atlantic and Gulf coasts of Florida to Veracruz, Mexico, while $M$. colei occurs on the $\mathrm{Yu}$ catan Peninsula, Mexico, where it is allopatric to other members of the genus (Fig. $1)$. In local areas on the Texas coast, $M$. beryllina and $M$. peninsulae hybridize extensively (Echelle et al., 1989). Although the hybrids we tested appear to be incapable of self-perpetuation by asexual reproduction (Echelle and Echelle, unpubl.), it seems likely that the $M$. clarkhubbsi complex originated via a similar hybridization system.

Because mtDNA has a rapid rate of sequence evolution (Brown et al., 1979; reviewed by Moritz et al. [1987]) and is maternally inherited (reviewed by Avise and Lansman [1983]), it has been especially useful in attempts to reconstruct the origins of unisexuality. To date, mtDNA analyses have been done on several unisexual lizards in the genera Cnemidophorus (Brown and Wright, 1979; Wright et al., 1983; Densmore et al., 1989a, 1989b; Moritz et al., $1989 a, 1989 b$ ) and Heteronotia (reviewed by Moritz et al. [1989a]) and on the unisexual fishes Poeciliopsis monacha-lucida (Avise and Vrijenhoek, 1987) and Phoxinus eos-neoqaeus (Goddard et al., 1989).

In this study, we used restriction-endonuclease analysis of mtDNA to characterize specimens from the two most common allozyme classes of the $M$. clarkhubbsi complex and the three bisexual species $(M$. beryllina, $M$. colei, and $M$. peninsulae) implicated in the ancestry of the unisexuals. Our primary purposes were to identify the maternal ancestry of the $M$. clarkhubbsi complex and to test the hypothesis that the unisexuals arose through multiple hybridizations. We also examined naturally occurring hybrids between $M$. beryllina and $M$. peninsulae to test for reciprocity of hybridization.

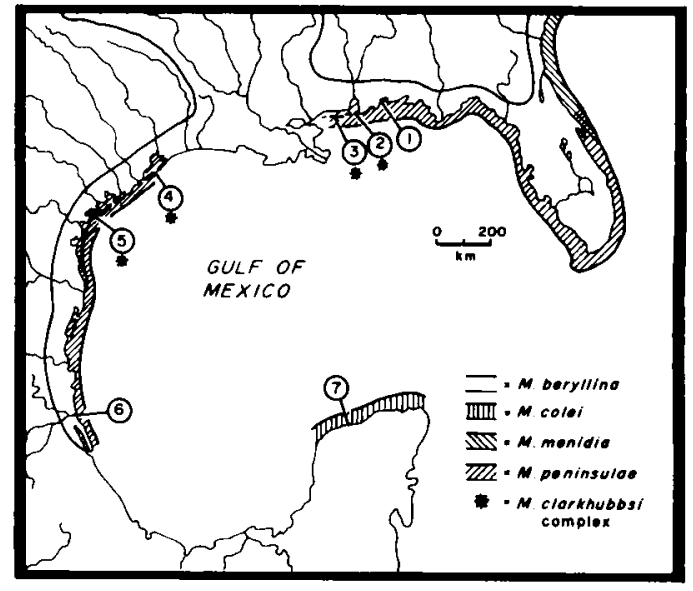

Fig. 1. Distributions of the $M$. clarkhubbsi complex and four bisexual species. Localities mentioned in the text are: $1=$ Pensacola Bay, Florida; $3=$ Horn Island, Mississippi; 4 = Galveston Pond, Texas; $5=$ Copano Bay, Texas; 6 = Lago de Pueblo Viejo, Veracruz, Mexico; 7 = Progresso, Yucatan, Mexico. Locality 2 (not mentioned in the text) marks the easternmost locality record for the unisexual complex (Echelle et al., 1989). The localities indicated for occurrence of the $M$. clarkhubbsi complex all refer to single sites of known occurrence, except for locality 5 , which refers to a large number of sites in coastal bays and estuaries centered around Copano Bay.

\section{Materials and Methods}

Protein electrophoresis, as described by Echelle et al. (1983, 1989), was used to identify $M$. beryllina, $M$. peninsulae, $M$. beryllina $\times M$. peninsulae hybrids, and different forms of the $M$. clarkhubbsi complex. Mitochondrial DNA was isolated from both fresh and frozen tissue samples. Frozen specimens had been stored at $-70^{\circ} \mathrm{C}$ for up to five years. DNA preparation and analysis followed Wright et al. (1983) and Dowling et al. (1989). All mtDNA samples were obtained from single individuals, except for those of $M$. colei. For $M$. colei, in which the available specimens were very small $(<25$ $\mathrm{mm}$ total length), six individuals were pooled for each DNA sample. Samples were digested with restriction endonucleases recognizing sequences of four (4-bp enzymes) or six (6-bp-enzymes) nucleotides (base recognition sequences in parentheses): $B a m \mathrm{H}$ I (GGATCC), Bcl I (TGATCA), Bgl II (AGATCT), BstE II (GGTNACC), Dde I (CTNAG), EcoR I (GAATTC), Hind III (AAGCTT), Hinf I (GANTC), HinP I (GCGC), Mbo I (GATC), Mlu I (ACGGCT), 
Nco I (CCATGG), Nhe I (GCTAGC), Pvu II (CAGCTG), Rsa I (GTAC), Sac I (GAGCTC), Sac II (CCGCGG), Spe I (ACTAGT), Taq I (TCGA), Xba I (TCTAGA), and Xho I (CTCGAG). End-labelling of mtDNA fragments, electrophoresis of digests in $1.0-1.6 \%$ agarose and $3.5-4.0 \%$ polyacrylamide gels, gel drying, and autoradiography were as described by Brown (1980) and Ferris et al. (1981). Estimates of sequence divergence from fragment comparisons were obtained using the equations in Avise et al. (1979) and clustered using the unweighted pair group method (UPGMA) of Sneath and Sokal (1973). The minimum-length network for the different $M$. clarkhubbsi and $M$. peninsulae haplotypes was constructed by hand and checked against the consensus of the first 100 mostparsimonious trees obtained with the PAUP and CONTREE computer programs distributed by D. Swofford (Phylogenetic Analysis Using Parsimony, version 2.4.1; available through Illinois Natural History Survey, Champaign).

We analyzed mtDNAs from 17 specimens of the $M$. clarkhubbsi complex. The specimens were from three localities, encompassing most of the known geographic range of the unisexual complex (Fig. 1): Fulton Pond in the Copano Bay area at Fulton, Aransas Co., Texas (three specimens of allozyme-class A), Galveston Pond at Galveston, Galveston Co., Texas (five specimens of allozyme-class A), and a pool on Horn Island, Mississippi (nine specimens, three of allozyme-class $A$ and six of class B). Specimens used were chosen randomly from each sample. Earlier surveys demonstrated that, except on Horn Island, allozyme-class A represented $84-100 \%$ of the unisexual forms. On Horn Island, approximately $30 \%$ of the unisexuals were of allozyme-class $B$. The other allozyme classes were rare $(1-7 \%$, typically $<3 \%)$ in the collections (Echelle et al., 1989), thus accounting for their absence in our analysis.

Because a preliminary mtDNA analysis suggested that the maternal ancestor of the $M$. clarkhubbsi complex was very similar to $M$. peninsulae, we examined samples of the latter from a wide geographic area. Nine specimens of $M$. peninsulae were examined: four from Fulton Pond, one from Galveston Pond, two from Horn Island, and one each from two additional localities (Pensacola Bay at Pensacola, Santa Rosa Co., Florida, and Lago de Puebla Viejo at Tampico, Veracruz, Mexico). We also examined mtDNA from nine specimens of $M$. beryllina (five from Fulton Pond, four from Galveston Pond), three hybrids between $M$. beryllina and $M$. peninsulae (one from Fulton Pond and two from Galveston Pond), and two samples (six individuals per sample) of $M$. colei from a bay at Progresso, Yucatan, Mexico. In addition, mtDNA data from four $M$. beryllina $\times M$. peninsulae hybrids taken from Galveston Pond were available from earlier restriction-fragment analyses done in I. Kornfield's laboratory.

\section{RESULTS}

Maternal Ancestry of the Unisexual Complex. - In a preliminary analysis of bisexual and unisexual specimens from two Texas localities (numbers 4 and 5 in Fig. 1), all of the unisexuals exhibited a Hind III pattern identical to that of $M$. peninsulae and different from that of $M$. beryllina. A subsequent analysis employing 14 additional 6-bp enzymes and 1-2 representatives of each taxon excluded both $M$. beryllina and $M$. cole $i$ and identified $M$. peninsulae as the maternal ancestor of the unisexual complex (Table 1; Figs. 2, 3). The two unisexuals chosen for the latter analysis represented different allozyme classes (" $A$ " and " $B$ " of Echelle et al., 1989). Only one restrictionsite change, an Spe I site loss in the representative of class $A$, was detected among the mtDNAs of $M$. peninsulae and the two unisexuals (Fig. 2). Of the 43-52 fragments produced, $96-100 \%$ were shared between $M$. peninsulae and the two unisexuals (Table 1). In contrast, the unisexuals shared only $51 \%$ and $72-73 \%$ of the fragments with $M$. beryllina and $M$. colei, respectively. The estimated sequence divergences were very low among the two unisexuals and $M$. peninsulae, but the sequence divergences between the unisexuals and $M$. cole $i$ and those between the unisexuals and $M$. beryllina, were eight and 20 times higher, respectively (Table 1, Fig. 3).

$m t D N A$ Diversity in the Unisexual Complex and M. peninsulae. - In a more detailed comparison, the mtDNAs of all specimens of $M$. peninsulae and the $M$. clarkhubbsi complex were assayed with six 


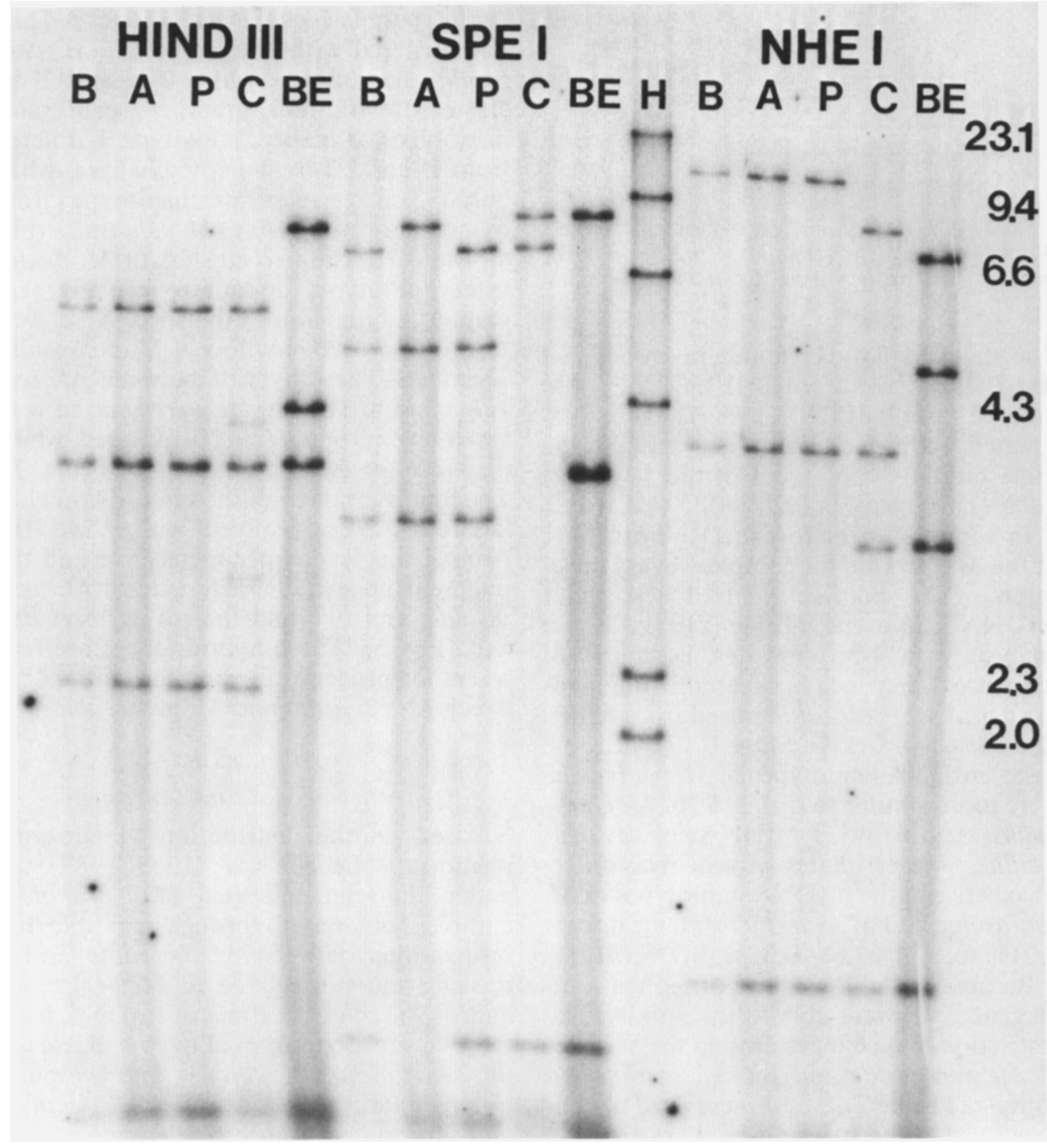

FIG. 2. Fragment patterns produced by digestion of mtDNA in $M$. beryllina (BE), M. colei (C), M. peninsulae $(\mathrm{P})$, and members of two allozyme classes (A and $\mathrm{B})$ of the $M$. clarkhubbsi complex with three restriction endonucleases. The size standard $(\mathrm{H})$ is Hind III-digested lambda DNA. Note that the fragment profiles for the $M$. clarkhubbsi complex are identical to those for $M$. peninsulae except for one site difference indicated by the Spe I pattern for profile A.

different 4-bp enzymes. These produced a total of 192-1 96 fragments per sample (e.g., Table 2). Three different mtDNA haplotypes were detected among the members of the $M$. clarkhubbsi complex. All 11 specimens of allozyme-class $A$, from three widely separated localities (numbers 3-5 in Fig. 1), had the same haplotype (I). Three different haplotypes occurred among the six representatives of class B, all from Horn Island
(Table 2): Four samples had the haplotype found in class $A(I)$, while the remaining two were unique (II and III). Thus, the specimens examined from the $M$. clarkhubbsi complex comprise a minimum of four forms, rather than the two recognized by allozymes alone. We refer to the various unisexual forms as A-I, B-I, B-II, and B-III.

The B-II and B-III mtDNA haplotypes were very similar, differing by only $0.04 \%$. 


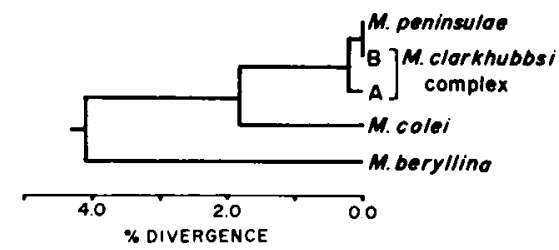

FIG. 3. UPGMA summary of sequence divergences (Table 1) among $M$. beryllina, $M$. colei, $M$. peninsulae, and two representatives of the $M$. clarkhubbsi complex.

The third haplotype, found in clones A-I and B-I, differed from B-II by $0.22 \%$ and differed from B-III by $0.35 \%$. The mean estimated sequence divergence among the three mtDNA haplotypes of the $M$. clarkhubbsi complex was $0.20 \%(\mathrm{SD}=0.16)$.

In contrast to the low mtDNA diversity of the $M$. clarkhubbsi complex, every specimen of $M$. peninsulae had a distinct mtDNA haplotype (Table 2). Based on analysis with 4-bp enzymes, estimates of sequence divergence between the nine haplotypes of $M$. peninsulae varied from $0.06 \%$ to $0.78 \%(\bar{x}=0.37 \%, \mathrm{SD}=0.17)$. In some cases, mtDNA haplotypes of $M$. peninsulae were more similar to mtDNAs of $M$. clarkhubbsi than to other mtDNAs of M. peninsulae. The estimates of sequence difference between the mtDNA haplotypes of $M$. peninsulae and $M$. clarkhubbsi ranged from $0.01 \%$ to $0.77 \%(\bar{x}=0.32 \%, \mathrm{SD}=0.17)$.

Because of the low levels of sequence divergence, we were able to infer individual restriction-site changes among the samples of $M$. peninsulae and the $M$. clarkhubbsi complex (Table 2). These were used to construct a minimum-length network (Fig. 4). The three mtDNA haplotypes of the $M$. clarkhubbsi complex were heterogeneous, clustering with two distinct groups of the haplotypes of $M$. peninsulae. Clones A-I and B-I clustered with one set of five $M$. peninsulae haplotypes, while B-II and B-III clustered with four other $M$. peninsulae haplotypes. Notably, haplotype I differed from II and III by 4-6 site changes, while only 1-3 changes separated haplotype I from four separate mtDNAs in M. peninsulae (Fig. 4, Table 2). The two clusters of $M$. peninsulae haplotypes do not reflect any geographic subdivision of the species.

Analysis of M. beryllina $\times$ M. peninsulae Hybrids. - Three hybrids between $M$. beryllina and $M$. peninsulae were assayed with two 6-bp enzymes, Hind III and Spe I, which diagnose the two parental species (Fig. 5). The four hybrids examined in I. Kornfield's laboratory were assayed with Hind III. Among the seven specimens, five had the fragment pattern characteristic of $M$. peninsulae, and two had that of $M$. beryllina (e.g., Fig. 5). These hybrids therefore represent the progeny of reciprocal matings between $M$. beryllina and $M$. peninsulae.

\section{Discussion \\ Identity of Maternal Ancestry}

Based on the distribution of allozyme phenotypes, Echelle et al. $(1983,1989)$ suggested that the unisexual $M$. clarkhubbsi complex originated through multiple hybridizations between $M$. beryllina and a missing ancestor related to $M$. peninsulae and/or $M$. colei. Analysis of mtDNA from the two most common allozyme classes of the $M$. clarkhubbsi complex and the putative parental species identifies $M$. peninsulae as the maternal ancestor, leaving $M$. beryllina as the paternal ancestor. Indeed, the mtDNAs of M. clarkhubbsi were more similar to some of the mtDNAs of $M$. penin-

TABLE 1. Variation among mtDNAs of two allozyme classes (A and B) of the $M$. clarkhubbsi complex and three bisexual species of Menidia, based on digests produced by 15 6-bp restriction enzymes. One mtDNA sample from each biotype is represented. The representative of allozyme-class B had haplotype III (Table 2). Total numbers of fragments for each sample are given in parentheses on the diagonal. Estimates of percentage sequence divergence are below the diagonal; percentage of fragments shared are above the diagonal.

\begin{tabular}{lccccc}
\hline \multicolumn{1}{c}{ Species } & 1A & 1B & 2 & 3 & 4 \\
\hline M. clarkhubbsi A & $(43)$ & 96.5 & 96.5 & 71.9 & 51.1 \\
M. clarkhubbsi B & 0.20 & $(44)$ & 100.0 & 73.3 & 50.5 \\
M. peninsulae & 0.20 & 0.00 & $(44)$ & 73.3 & 50.5 \\
M. colei & 1.88 & 1.76 & 1.76 & $(48)$ & 46.5 \\
M. beryllina & 3.91 & 3.98 & 3.98 & 4.49 & $(52)$ \\
\hline
\end{tabular}


sulae than the latter were to one another. Given the small number of $M$. peninsulae analyzed $(N=9)$ and the diversity of mtDNAs within this species, it is possible that further sampling would produce individuals of $M$. peninsulae with the exact mtDNA haplotypes detected in $M$. clarkhubbsi.

Allozymic and mtDNA data both indicate that the $M$. clarkhubbsi complex arose from multiple hybridizations between $M$. beryllina and $M$. peninsulae. The allozymically determined genotypic variation among the unisexuals conforms with allelic polymorphisms present in one or both of the parental species (Echelle et al., 1989). The three mtDNA haplotypes detected in the unisexual complex cluster with two different assemblages of mtDNAs from $M$. peninsulae (Fig. 4), suggesting a minimum of two maternal origins. A more extensive survey might have provided further evidence for multiple origins. Our analysis probably underestimates mtDNA diversity in the unisexuals, as relatively few specimens were examined and the rarer allozyme classes were excluded. Multiple origins are characteristic of most complexes of unisexual

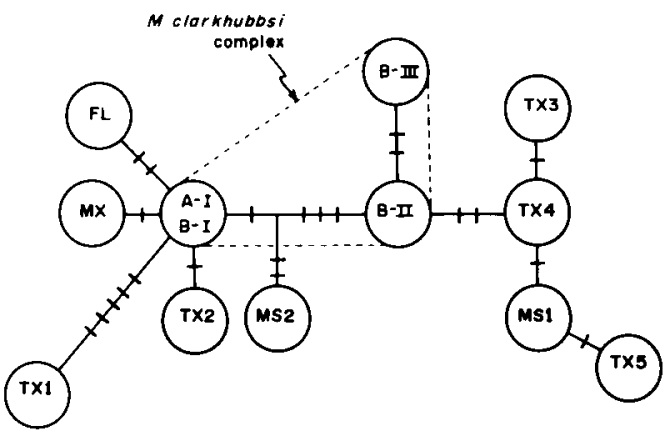

FIG. 4. Minimum-length network connecting the 12 mtDNA haplotypes in the $M$. clarkhubbsi complex and $M$. peninsulae. A-I and B-I denote two allozyme classes (A and B) having the same mtDNA haplotype (I). The network is based on the inferred restrictionsite changes shown in Table 2 . Each bar signifies a site gain or loss; lengths of connecting lines are proportional to the numbers of site changes. The network contains no homoplasies.

vertebrates (Vrijenhoek, 1979; Moritz et al., 1989a; Goddard et al., 1989).

Some details of the allozyme data conflict with the conclusion that $M$. peninsulae is the maternal ancestor of the $M$. clarkhubbsi complex. Two non-beryllina alleles present in the unisexual complex have not been de-

TABLE 2. Mitochondrial-DNA haplotypes of 17 specimens of the $M$. clarkhubbsi complex and nine specimens of $M$. peninsulae. For each restriction enzyme, "A" denotes the most common pattern. Each of the other letters symbolizes one site change relative to the A pattern-site losses in lower case, site gains in upper case. Only those restriction enzymes used with all specimens of the unisexual complex and $M$. peninsulae are shown. Haplotypes are given acronyms corresponding with the state or country of collection: $\mathrm{MX}=$ Veracruz, Mexico; TX1-TX4 = Fulton Pond, Texas; TX5 = Galveston Pond, Texas; MS1-MS2 = Horn Island, Mississippi; FL = Pensacola, Florida. For the numbers of individuals, the letters $\mathrm{A}$ and B signify members of the two allozyme classes ("clones" A and B in Echelle et al. [1989]).

\begin{tabular}{|c|c|c|c|c|c|c|c|c|c|}
\hline \multirow[b]{2}{*}{ Haplotype } & \multirow{2}{*}{$\begin{array}{l}\text { Number of } \\
\text { individuals }\end{array}$} & \multirow{2}{*}{$\begin{array}{l}\text { Number } \\
\text { of sites }\end{array}$} & \multicolumn{7}{|c|}{ Enzyme } \\
\hline & & & Mbo I & Dde I & Hinp I & Hinf I & Hind III & Rsa I & Taq I \\
\hline \multicolumn{10}{|c|}{ M. clarkhubbsi: } \\
\hline I & $11 A, 4 B$ & 194 & A & $\mathbf{A}$ & $\mathbf{A}$ & $\mathbf{A}$ & $\mathbf{A}$ & Bcd & $\mathbf{A}$ \\
\hline II & 1 B & 196 & B & A & A & $\mathbf{A}$ & $\mathbf{A}$ & A & A \\
\hline III & $1 \mathrm{~B}$ & 194 & $\mathrm{Bc}$ & $\mathrm{b}$ & A & $\mathbf{A}$ & $\mathbf{A}$ & A & $\mathbf{A}$ \\
\hline \multicolumn{10}{|c|}{ M. peninsulae: } \\
\hline MX & 1 & 193 & A & $\mathbf{A}$ & $\mathbf{b}$ & $\mathbf{A}$ & A & Bcd & $\mathbf{A}$ \\
\hline $\mathrm{TX} 1$ & 1 & 193 & d & $\mathbf{A}$ & A & bc & B & Ebcd & A \\
\hline $\mathbf{T X} 2$ & 1 & 195 & A & $\mathbf{A}$ & $\mathbf{A}$ & $\mathbf{A}$ & C & Bcd & $\mathbf{A}$ \\
\hline TX3 & 1 & 193 & Bef & $c$ & A & $\mathbf{A}$ & $\mathbf{A}$ & A & $\mathbf{A}$ \\
\hline TX4 & 1 & 194 & $\mathrm{Be}$ & $\mathrm{c}$ & $\mathbf{A}$ & $\mathbf{A}$ & $\mathbf{A}$ & $\mathbf{A}$ & $\mathbf{A}$ \\
\hline TX5 & 1 & 192 & $\mathrm{Be}$ & cd & $\mathrm{c}$ & A & $\mathbf{A}$ & A & A \\
\hline MS1 & 1 & 193 & $\mathrm{Be}$ & cd & $\mathbf{A}$ & A & $\mathbf{A}$ & A & A \\
\hline MS2 & 1 & 195 & Gh & A & A & A & $\mathbf{A}$ & A & $\mathbf{A}$ \\
\hline $\mathbf{F L}$ & 1 & 192 & A & e & d & $\mathbf{A}$ & $\mathbf{A}$ & Bcd & $\mathbf{A}$ \\
\hline
\end{tabular}




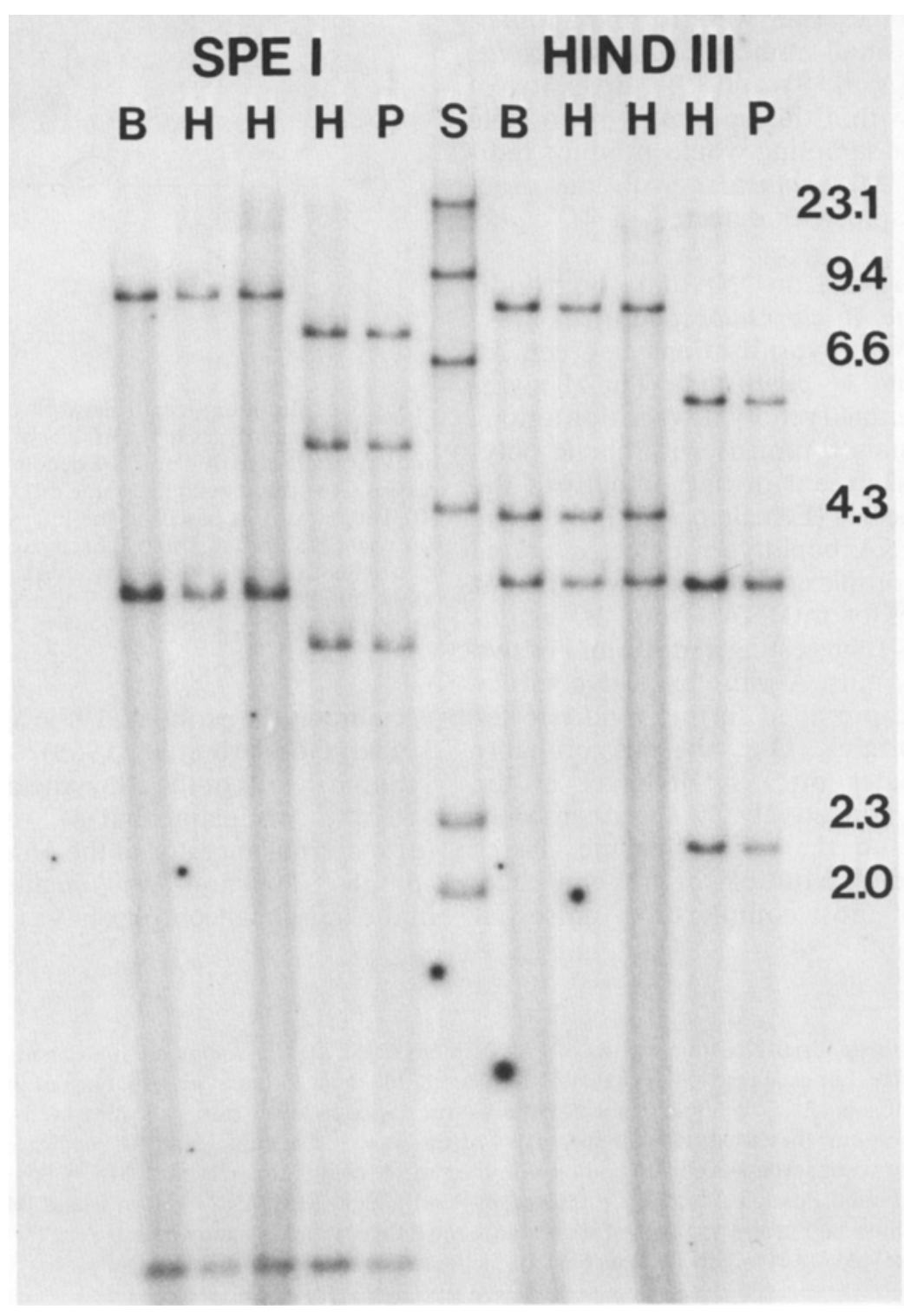

Fig. 5. Fragment patterns produced by Hind III and Spe I digestion of mtDNA in $M$. beryllina (B), three $M$. beryllina $\times M$. peninsulae hybrids $(\mathrm{H})$, and $M$. peninsulae $(\mathrm{P})$. Note that the hybrids exhibit patterns of both $M$. peninsulae and $M$. beryllina.

tected in $M$. peninsulae, despite extensive sampling over almost the entire geographic range of the species (Echelle et al., 1989). One of those alleles, $P g m-A^{d}$ is found in all clones of the $M$. clarkhubbsi complex but is not known in any bisexual species (Johnson, 1975; Mosier, 1979; Echelle et al., 1983, 1989; Duggins et al., 1986), including a group (Chirostoma) possibly congeneric with Menidia (Echelle and Echelle, 1984). The other non-beryllina allele, Icdh- $A^{e}$ occurs in five of the ten clones (A, B, D, E, and F) and is otherwise restricted to $M$. colei, except for rare (frequency $<0.05$ ) occurrence in $M$. beryllina.

Given that $M$. peninsulae contributed the mtDNA of the unisexuals, there are two available hypotheses for the occurrence of the "orphan alleles" (Turner, 1982) described above: 1) mutation within the uni- 
sexual form and 2) inheritance from an uncharacterized population of $M$. peninsulae. The latter could be an extant geographic variant or a now-extinct form. Each explanation poses difficulties. Because the orphan alleles are widespread in the unisexual complex, the mutation hypothesis requires occurrence of mutations in a single ancestral clone. However, the allozyme and mtDNA data indicate that there was no such ancestral clone: $M$. clarkhubbsi apparently had multiple hybrid origins. It is also unlikely that the orphan alleles were inherited from an extant geographic variant of $M$. peninsulae. The extensive surveys of $M$. peninsulae (Johnson, 1975; Echelle et al., 1983, 1989; Duggins et al., 1986) reveal no evidence of geographically structured polymorphism. The remaining possibility is that the orphan alleles were inherited from a nowextinct form of $M$. peninsulae. Given the close similarity between the mtDNAs of the unisexual complex and those of extant $M$. peninsulae, the postulated extinction must have been very recent.

\section{Constraints on Hybrid Origins of Unisexual Menidia}

The successful origin of unisexual reproduction by hybridization has been likened to macromutation or a cytological tour de force (White, 1978). It has been very difficult to recreate unisexual hybrid lineages in the laboratory (Schultz, 1973; White et al., 1977; Drosopolous, 1978; Turner, 1982; Wetherington et al., 1987). Together with the rarity of unisexual vertebrates, this indicates strong cytological and developmental constraints on unisexual lineages of hybrid origin, such that they are rarely formed or ephemeral (Wetherington et al., 1987; Moritz et al., 1989a). In this respect, analyses of Menidia are potentially valuable, because $F_{1}$ hybrids are abundant. It may be possible to identify some of the cytological and developmental constraints by inferring the frequency and form of hybrid origins from genetic data and by comparing the reproductive properties of the existing $\mathrm{F}_{1}$ hybrids between $M$. beryllina and $M$. peninsulae to those of the $M$. clarkhubbsi complex.

Mitochondrial-DNA analysis of Menidia provides two indications that unisexuals are not randomly formed or produced at high frequency. First, the unisexuals only have a peninsulae-like form as the maternal parent, whereas viable $\mathrm{F}_{1}$ hybrids between $M$. beryllina and $M$. peninsulae are produced by reciprocal matings. The nonreciprocity seen in Menidia has been observed in many (although not all) unisexual vertebrates (Schultz, 1973, 1977; Brown and Wright, 1979; Wright et al., 1983; Densmore et al., 1989a, 1989b; Goddard et al., 1989; Moritz et al., 1989a, 1989b). Where nonreciprocity has been observed, it is possibly a statistical artifact stemming from the rarity of hybrid origins of new unisexual forms; however, biological explanations should be explored where there is evidence for multiple hybrid origins.

The second indication that unisexual formation is both rare and specific stems from the observation that unisexual Menidia exhibit much lower mtDNA diversity than their maternal parent, $M$. peninsulae. Most unisexual vertebrates studied have substantially reduced mtDNA diversity relative to their maternal parents (Densmore et al., 1989a, 1989b; Moritz et al., 1989a, 1989b). Such limited sampling of the variation present in the bisexual species suggests that the hybridization events that lead to the establishment of unisexual lineages are rare. Two exceptions to this are fishes of the genera Poeciliopsis (Avise and Vrijenhoek, 1987) and Phoxinus (Goddard et al., 1989), among which the diverse mtDNA haplotypes found in the unisexuals match local variants of the bisexuals. Interestingly, unisexual Poeciliopsis can still be generated by hybridization (Schultz, 1973), albeit at low efficiency (Wetherington et al., 1987). Attempts have not yet been made to synthesize unisexual Phoxinus.

Three cytological/developmental attributes are necessary for the establishment of new gynogenetic lineages: 1) the production of unreduced eggs, 2) avoidance of syngamy, and 3) sufficiently high fecundity and viability. $\mathrm{F}_{1}$ hybrids between $M$. peninsulae and $M$. beryllina produce unreduced eggs; however, the hybrids have low fecundity, and the few eggs produced fail to avoid syngamy (A. A. Echelle and A. F. Echelle, unpubl.). Sunfish hybrids provide a similar example (Dawley et al., 1985). This obser- 
vation, together with the possibility that a now-extinct form of $M$. peninsulae was involved in producing the $M$. clarkhubbsi complex, is consistent with recent models (Vrijenhoek and Lerman, 1982; Wetherington et al., 1987; Moritz et al., 1989a) relating the stage of divergence between two species to the probability that hybrids between them will form unisexual lineages. Divergence must be sufficient to deregulate the genetic control of meiosis, causing the production of eggs with unreduced chromosome numbers, but not so high that fertility or viability is severely reduced. In Menidia, the currently hybridizing species may have diverged to a point where the formation of new unisexual clones is highly unlikely.

\section{ACKNOWLEDGMENTS}

We are grateful to A. F. Echelle for assistance with the allozyme work, for comments on the manuscript, and for help in collecting specimens; to I. Kornfield for contributing mtDNA data on hybrids; to $S$. $T$. Ross for help in gaining access to Horn Island; to V. Singh and D. Vyas for help with the mtDNA analyses; and to F. Kraus for reviewing the manuscript. Partial support was provided by grant BSR-8314139 from the National Science Foundation to A.A.E. The mtDNA analyses were supported by NSF grants BSR-8516812 to T.E.D. and G. R. Smith, BSR-8517830 to W.M.B. and C.M., and BSR-8576645 to W.M.B. and W. R. Dawson.

\section{Literature Cited}

Avise, J. C., G. Giblin-Davidson, J. Laerm, J. C. Patton, and R. A. Lansman. 1979. Mitochondrial DNA clones and matriarchal phylogeny within and among geographic populations of the pocket gopher, Geomys pinetis. Proc. Nat. Acad. Sci. USA 76:6694-6698.

Avise, J. C., ANd R. A. Lansman. 1983. Polymorphism of mitochondrial DNA in populations of higher animals, pp. 147-164. In M. Nei and R. K. Koehn (eds.), Evolution of Genes and Proteins. Sinauer, Sunderland, MA.

Avise, J. C., AND R. C. VRIJenhoek. 1987. Mode of inheritance and variation of mitochondrial DNA in hybridogenetic fishes of the genus Poeciliopsis. Molec. Biol. Evol. 4:514-525.

BeLL, G. 1982. The Masterpiece of Nature. CroomHelm, London, U.K.

Brown, W. M. 1980. Polymorphism in mitochondrial DNA of humans as revealed by restriction endonuclease analysis. Proc. Nat. Acad. Sci. USA 77:3605-3609.

Brown, W. M., M. George, JR., and A. C. Wilson. 1979. Rapid evolution of animal mitochondrial DNA. Proc. Nat. Acad. Sci. USA 76:1967-1971.

BRoWN, W. M., AND J. WRIGHT. 1979. Mitochondrial DNA analyses and the origin and relative age of parthenogenetic lizards (genus Cnemidophorus). Science 203:1247-1249.

COLE, C. J. 1975. Evolution of parthenogenetic species of reptiles, pp. 340-355. In R. Reinboth (ed.), Intersexuality in the Animal Kingdom. Springer-Verlag, N.Y.

Darevsky, I. S., L. A. Kupriyanova, and T. Uzzell. 1985. Parthenogenesis in reptiles, pp. 412-526. In C. Gans and F. Billett (eds.), Biology of the Reptilia. Wiley, N.Y.

Dawley, R. M., AND J. P. Bogart (Eds.). 1989. Evolution and Ecology of Unisexual Vertebrates. New York State Museum, Albany.

Dawley, R. M., J. H. Graham, and R. J. Schultz. 1985. Triploid progeny of pumpkinseed $\times$ green sunfish hybrids. J. Hered. 78:251-257.

DenSMORE, L. D., C. Moritz, J. W. Wright, AND W. M. Brown. 1989a. Mitochondrial-DNA analyses and the origin and relative age of parthenogenetic lizards (genus Cnemidophorus). IV. Nine sexlineatus-group parthenoforms. Evolution 43:969-983.

Densmore, L. D., J. W. WRight, AND W. M. BROWN. 1989b. Mitochondrial-DNA analyses and the origin and relative age of parthenogenetic lizards (genus Cnemidophorus). II. C. neomexicanus and the C. tesselatus complex. Evolution 43:943-957.

Dowling, T. E., G. R. Smith, and W. M. Brown. 1989. Reproductive isolation and introgression between Notropis cornutus and Notropis chrysocephalus (Family Cyprinidae): Comparison of morphology, allozymes and mitochondrial DNA. Evolution 43:620-634.

Drosopolous, S. 1978. Laboratory synthesis of a pseudogamous triploid species of the genus $\mathrm{Mul}$ lerianella (Homoptera, Delphacidae). Evolution 32: 916-920.

Duggins, C. F., Jr., A. A. Karlin, K. Relyea, and R. W. YERGER. 1986. Systematics of the Key silverside, Menidia conchorum, with comments on other Menidia species (Pisces: Atherinidae). Tulane Stud. Zool. Bot. 25:133-150.

Echelle, A. A., AND A. F. Echelle. 1984. Evolutionary genetics of a "species flock": Atherinid fishes on the Mesa Central of Mexico, pp. 93-110. In A. A. Echelle and I. Kornfield (eds.), Evolution of Fish Species Flocks. Univ. Maine Press, Orono.

Echelle, A. A., A. F. Echelle, And C. D. Crozier. 1983. Evolution of an all-female fish, Menidia clarkhubbsi (Atherinidae). Evolution 37:772-784.

Echelle, A. A., A. F. Echelle, L. E. DeBault, and D. W. Durham. 1988. Ploidy levels in silverside fishes (Atherinidae, Menidia) on the Texas coast: Flow-cytometric analysis of the occurence of allotriploidy. J. Fish Biol. 32:835-844.

Echelle, A. A., A. F. Echelle, ANd D. P. Middaugh. 1989. Evolutionary biology of the Menidia clarkhubbsi complex of unisexual fishes (Atherinidae): Origins, clonal diversity, and mode of reproduction, pp. 144-152. In R. M. Dawley and J. P. Bogart 
(eds.), Evolution and Ecology of Unisexual Vertebrates. New York State Museum, Albany.

Ferris, S. D., W. M. Brown, W. S. Davidson, AND A. C. WILSON. 1981. Extensive polymorphism in the mitochondrial DNA of apes. Proc. Nat. Acad. Sci. USA 78:6319-6323.

Goddard, K. A., R. M. DAWley, ANd T. E. Dowling. 1989. Origin and genetic relationships of diploid, triploid, and diploid-triploid mosaic biotypes in the Phoxinus eos-neogaeus unisexual complex, pp. 268280. In R. M. Dawley and J. P. Bogart (eds.), Evolution and Ecology of Unisexual Vertebrates. New York State Museum, Albany.

JoHnson, M. S. 1975. Biochemical systematics of the atherinid genus Menidia. Copeia 1975:662-691.

LYNCH, M. 1984. Destabilizing hybridization, general purpose genotypes and geographic parthenogenesis. Quart. Rev. Biol. 59:257-290.

MaYNaRd Smith, J. 1978. The Evolution of Sex. Cambridge Univ. Press, N.Y.

Moritz, C., W. M. Brown, L. D. Densmore, J. W. Wright, D. Vyas, S. DonNellan, M. Adams, and P. BAVERSTOCK. 1989a. Genetic diversity and the dynamics of hybrid parthenogenesis in Cnemidophorus (Teiidae) and Heteronotia (Gekkonidae), pp. 87-1 12. In R. M. Dawley and J. P. Bogart (eds.), Evolution and Ecology of Unisexual Vertebrates. New York State Museum, Albany.

MorIT, C., T. E. Dowling, AND W. M. Brown. 1987. Evolution of animal mitochondrial DNA: Relevance for population biology and systematics. Ann. Rev. Ecol. Syst. 18:269-292.

MORIT, C., J. W. WRIGHT, AND W. M. BROWN. $1989 b$. Mitochondrial-DNA analyses and the origin and relative age of parthenogenetic lizards (genus Cnemidophorus). III. $C$. velox and $C$. exsanguis. Evolution 43:958-968.

Mosier, D. T. 1979. Genetic studies of Menidia (Pisces: Atherinidae) populations on the Gulf Coast of Texas. M.S. Thesis. Baylor Univ., Waco, TX.
Schultz, R. J. 1973. Unisexual fish: Laboratory synthesis of a "species." Science 179:180-181.

- 1977. Evolution and ecology of unisexual fishes. Evol. Biol. 10:277-331.

SNEATH, P. H. A., AND R. R. SOKAL. 1973. Numerical Taxonomy. Freeman, San Francisco, CA.

Templeton, A. R. 1982 . The prophecies of parthenogenesis, pp. 75-101. In H. Dingle and J. P. Hegmann (eds.), Evolution and Genetics of Life Histories. Springer-Verlag, N.Y.

TURNER, B. J. 1982. The evolutionary genetics of a unisexual fish, Poecilia formosa, pp. 265-305. In C. Barigozzi (ed.). Liss, N.Y.

VRIENHOEK, R. C. 1979. Factors affecting clonal diversity and coexistence. Amer. Zool. 19:787-797.

VRuenhoek, R. C., AND S. Lerman. 1982. Heterozygosity and developmental stability under sexual and asexual breeding systems. Evolution 36:768776.

Wetherington, J. D., K. E. Kotora, AND R. C. VRIJENHOEK. 1987. A test of the spontaneous-heterosis hypothesis for unisexual vertebrates. Evolution 41:721-731.

Whrte, M. J. D. 1978 . Modes of Speciation. Freeman, San Francisco, CA.

White, M. J. D., N. Contreras, J. Cheney, and G. C. WEBB. 1977. Cytogenetics of the parthenogenetic grasshopper Warramaba (formerly Moraba) virgo and its bisexual relatives. II. Hybridization studies. Chromosoma 61:127-148.

Williams, G. C. 1975. Sex and Evolution. Princeton Univ. Press, Princeton, NJ.

Wright, J. W., C. Spolsky, AND W. M. Brown. 1983. The origin of the parthenogenetic lizard Cnemidophorus laredoensis inferred from mitochondrial DNA analysis. Herpetologica 39:410-416.

Corresponding Editor: C. F. Aquadro 